\title{
Distal perforator based cross leg flaps for leg and foot defects
}

\author{
V. Bhattacharya, Ganji Raveendra Reddy \\ Department of Plastic Surgery, Institute of Medical Sciences, Banaras Hindu University, Varanasi, India
}

Address for correspondence: Prof. V. Bhattacharya, B-33/14-16, Gandhi Nagar, Naria, Varanasi - 221005, India. E-mail: visweswar1@rediffmail.com

\begin{abstract}
The cross leg fasciocutaneous flaps are less frequently indicated for distal leg and foot defects due to the availability of other alternative options. However they still remain one of the more realistic options for the surgeon in situations like unsuccessful attempt of free flaps, non-availability of ipsilateral proximal calf tissue, damaged distal perforators following trauma, burns, radiation etc., and inadequate reach beyond mid sole. In the present article we share our experience emphasizing the significance and use, with redefined indications and surgical technique of cross leg retrograde fasciocutaneous flaps for various distal leg and foot defects. We are of the opinion that these flaps are still useful as they continue to prove to be the flap of choice in demanding situations.
\end{abstract}

\section{KEY WORDS}

Perforator flaps, Cross leg flaps, Retrograde flaps

\section{INTRODUCTION}

ross leg fasciocutaneous flaps ${ }^{1}$ are not considered frequently in current medical practice due to the availability of other ipsilateral flaps like fasciocutaneous flaps, ${ }^{2}$ muscle and musculocutaneous flaps. ${ }^{3}$ and free flaps. ${ }^{4}$ However, in certain situations they still remain the flap of choice. Usually distal limb defects are managed either by ipsilateral retrograde flaps or free flaps. Nevertheless there are situations where ipsilateral flaps are not feasible or the surgeon may not consider another free flap after an unsuccessful attempt. On such infrequent occasions the retrograde cross leg fasciocutaneous flaps based on the perforators of posterior tibial ${ }^{5}$ and peroneal arteries $^{6}$ provide considerable dimension of tissue to cover most of the distal leg and foot defects. If properly planned, it allows mobility between the two limbs, minimizing the cross legging and pressure sore on either limb as well as avoiding tension over the flap. We are presenting our experience with these flaps in 12 cases, for various distal leg and foot defects.

\section{MATERIALS AND METHODS}

\section{Indications}

The selective indications where such flaps were used are

1. Unsuitable proximal calf tissue for ipsilateral retrograde fasciocutaneous flaps

2. Damaged ipsilateral distal perforators following trauma, burns, radiotherapy etc.

3. Very distal defects where ipsilateral retrograde flaps could not reach

\section{Contraindications}

Medical disorders like diabetes, hypertension, and 
previous history of thrombosis are not favorable conditions and due merit should be given to the morbidity in a given patient. However, stiffness in either leg preventing a suitable positioning is an absolute contraindication $^{7}$ for this procedure.

\section{Planning}

Before planning these flaps prior counseling of patients and their attendants is essential, regarding available options, position of the limb, required nursing care, period of hospitalization and morbidity of the donor site. This helps in gaining their confidence and cooperation. Meticulous planning is needed where attention is paid to the position of the donor limb with relaxed pedicle to prevent tension on the flap and avoiding cross legging. The principle of 'planning in reverse' is most appropriately applied in this case.

Depending on the suitability, either posterior tibial artery (Medial flap) or peroneal artery (Lateral flap) distal perforator perfused retrograde fasciocutaneous flap was selected. In all the cases perforators were identified prior to surgery by hand held Doppler. ${ }^{8}$ The base of the flaps was kept at about $8 \mathrm{~cm}$ from the respective malleoli, as we noticed that there were almost always constant perforators ${ }^{9}$ between 4 and $8 \mathrm{cms}$. The upper limit of the flap was kept 8-10 cms from the knee joint line. The breadth of the flap depended on the dimension of the defect, with the maximum being up to mid calf line posteriorly [Figure 1].

\section{Surgical technique}

Surgery was performed under either spinal or epidural anesthesia and tourniquet was used on the donor limb while harvesting the flaps. The incision was made on three sides making the flap narrow distally towards the base. Dissection was done subfascially in the surgical plane ${ }^{10}$ ligating all the proximal perforators. After harvesting the flap the reach was confirmed by bringing the donor limb along with the flap to the defect keeping the limbs in comfortable position [Figure 2a, 2b]. Before insetting the flap, the donor area and the under surface of the bridge segment of the flap were covered with split thickness skin grafts. The limbs were immobilized both proximally and distally. The fixation was achieved by few layers of a Plaster of Paris bandage in the form of figure of eight around two light smooth wooden pieces of half an inch diameter and eighteen inches long. These were kept with adequate cotton padding across the ankle and knee. Since the primary insetting was more than $70 \%$, single stage flap detachment was done after three weeks. In most of the cases bridge segment was utilized to resurface rest of the recipient area and in the remaining cases it was brought back to the donor limb. Active and passive movements of the limbs were encouraged soon after detachment.

\section{RESULTS}

Over a period of 14 years (from 1990-2003), 12 contralateral retrograde fasciocutaneous flaps were done [Table 1]. Male female ratio was 5:1 (10:2). The age group ranged from 11 years to 51 years with an average of 31 years. The varied etiology included trauma (8), unstable scar (1), post burn ulcer (2), and post irradiation defect (1). The average size of the defect was $10 \times 10 \mathrm{~cm}^{2}$. The various sites of the defect were distal leg with fracture both bones (4), distal leg following radiotherapy (1), avulsion injury of sole (2), unstable scar over heel (3) and dorsum of foot (2). In seven patients medial flaps were used and in five, lateral flaps. Marginal necrosis of 1-2 $\mathrm{cm}$ was noticed in two cases which healed conservatively. The follow up period ranged from 15 months to 14 years [Figure 3a, 3b].

Table 1: Patient profile

\begin{tabular}{|c|c|c|c|c|c|c|c|}
\hline Sex & Age & Aetiology & DefectSite & $\begin{array}{l}\text { Defect size } \\
\text { (cms) (LXB) }\end{array}$ & $\begin{array}{l}\text { Flapsize } \\
\text { (cms) (LXB) }\end{array}$ & $\begin{array}{l}\text { Flap type } \\
\text { (Medial/Lateral) }\end{array}$ & Complication \\
\hline M & 30 & Trauma & Distal leg & $10 \times 11$ & $22 \times 11$ & M & Uneventful \\
\hline M & 49 & Unstable scar & Heel & $11 \times 12$ & $22 \times 12$ & $M$ & Uneventful \\
\hline M & 27 & Trauma & Distal leg & $11 \times 10$ & $21 \times 12$ & $\mathrm{~L}$ & Uneventful \\
\hline $\mathrm{F}$ & 18 & Post radiation & Distal leg & $10 \times 10$ & $22 \times 12$ & $M$ & Uneventful \\
\hline M & 33 & Trauma & Sole & $12 \times 11$ & $24 \times 14$ & $\mathrm{~L}$ & $2 \mathrm{~cm}$ marginal necrosis \\
\hline M & 21 & Trauma & Sole & $12 \times 11$ & $24 \times 11$ & M & $1 \mathrm{~cm}$ marginal necrosis \\
\hline M & 29 & Trauma & Heel & $12 \times 10$ & $22 \times 11$ & $\mathrm{~L}$ & Uneventful \\
\hline M & 21 & Trauma & Distal leg & $10 \times 10$ & $22 \times 11$ & M & Uneventful \\
\hline M & 29 & Trauma & Heel & $12 \times 10$ & $22 \times 11$ & $\mathrm{~L}$ & Uneventful \\
\hline
\end{tabular}




\section{DISCUSSION}

The era of cross leg flaps can be divided into three periods. 1. Before Ponten ${ }^{11}(<1981)$ 2. Ponten ${ }^{12}$ (1981) and 3. After Ponten (>1985/90). ${ }^{13}$ Before Ponten the cross leg flaps were mere skin flaps without inclusion of deep fascia with limited length breadth ratio (1:1). To enhance the length, 'delay' was necessary, which increased the number of procedures and thereby hospitalization for several weeks. The bridge segment was kept as minimum as possible and to avoid tension, limbs were crossed maximally. The incidence of development of joint stiffness and sores were high. The flaps were detached in stages. Later, Ponten (1981) described 'super flaps' with inclusion of deep fascia augmenting the circulation. These fasciocutaneous flaps then had the liberty of 3:1 ratio. This provided more room for movement between limbs

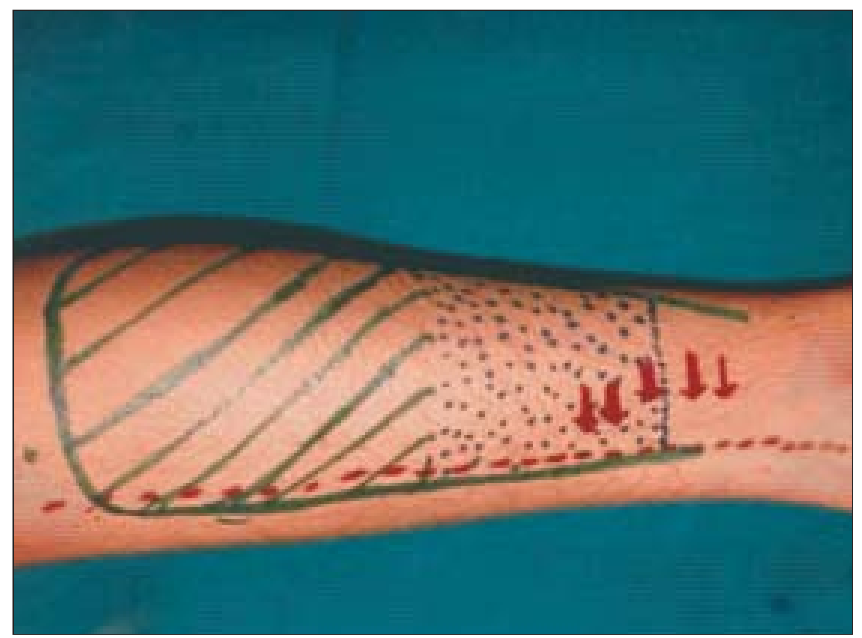

Figure 1a: Planning of cross leg flap on the contralateral limb showing position of perforators, bridge segment and effective flap for reconstruction

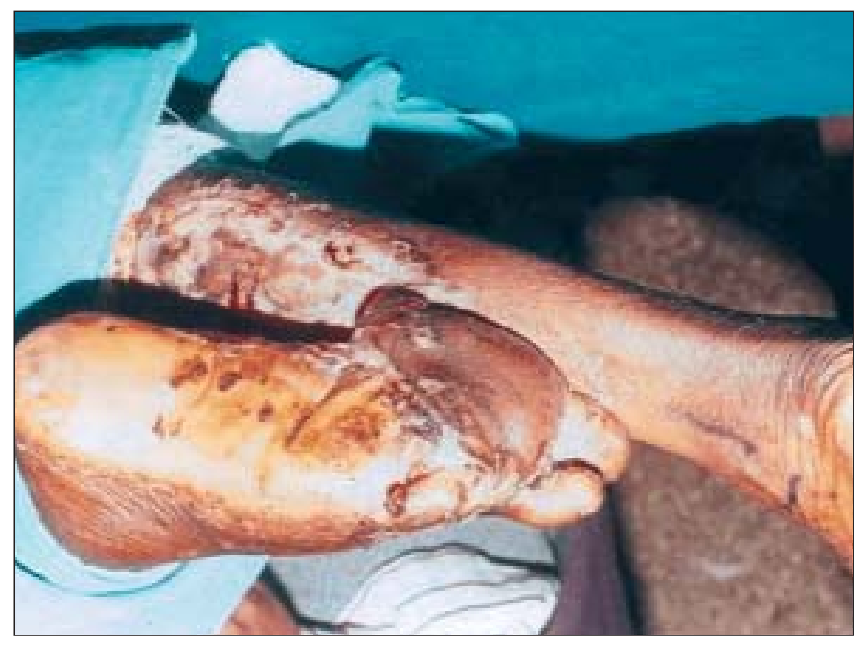

Figure 1b: Planning of cross leg flap on the contralateral limb showing position of perforators, bridge segment and effective flap for reconstruction avoiding cross legging with minimal discomfort and inconvenience to the patient. Delay and division of the

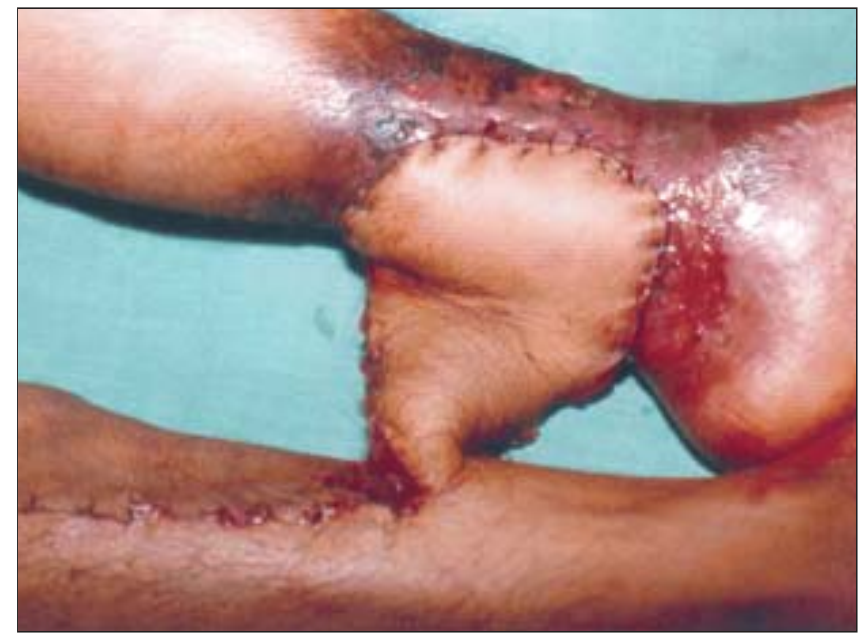

Figure 2: Cross leg flaps for resurfacing (Figure 2a) distal sole, (Figure 2b) post irradiated scar of distal leg

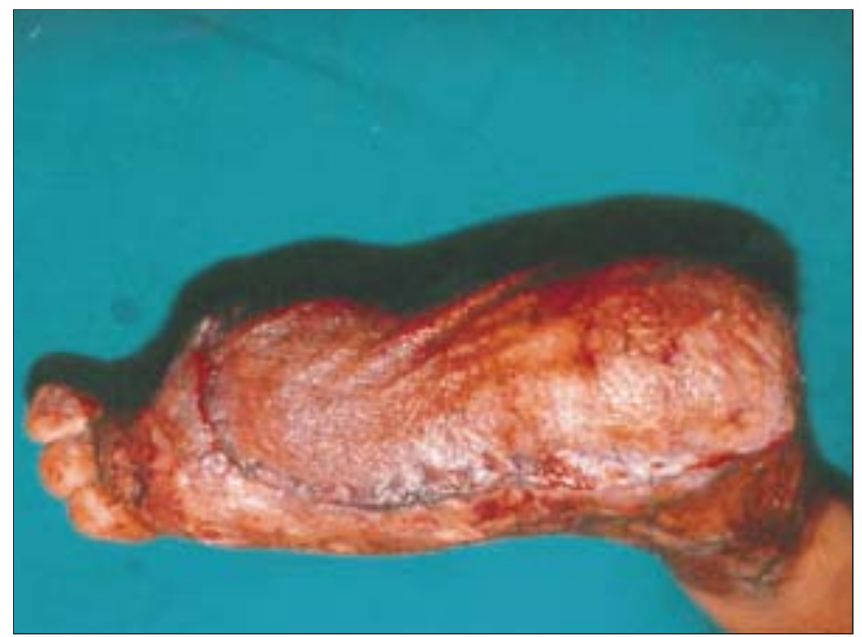

Figure 3a: Follow up results

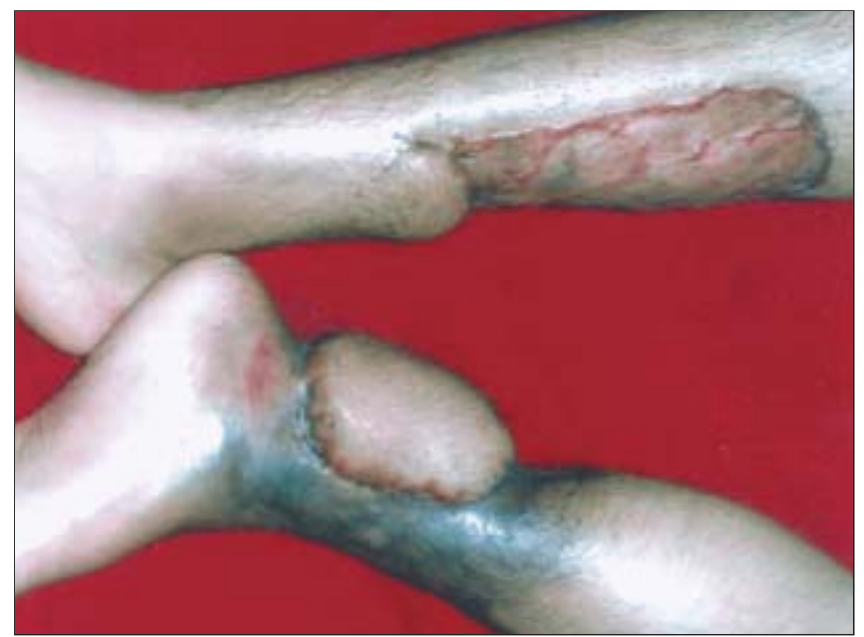

Figure 3b: Follow up results 
flap in stages became optional.

Further, in the late 1980's with improved understanding of the vascularity of the soft tissue of the leg based on the perforators, fasciocutaneous flaps based on these perforators with a non conventional dimension of more than 3:1 ratio were designed. These perforator based flaps have certain major advantages over the conventional cross leg flaps. Being perforator flaps, the pedicle can be narrowed, allowing more mobility and easy transfer. As the positions of the perforators are almost always constant, they are reliable. Since these perforators are adequate to supply significant amounts of the proximal tissue no delay is required. Thus, the hospital stay and morbidity is reduced. The calf tissue in an adult is usually enough to cover large defects and even the total sole. The long bridge segment provides adequate mobility between the limbs avoiding stiffness and joint contractures and the cross legging is minimal. Retrograde cross leg flaps based on distal perforators were infrequently done for selective distal defects as most of them were managed either by ipsilateral or free flaps.

In our series, all the flaps were detached in a single stage as their primary insetting was more than $70 \%$ and therefore reduced the overall discomfort to the patient as well as period of hospitalization. The site and position of the perforators have been confirmed earlier by our own cadaveric dissection ${ }^{14,15}$ and also by others. ${ }^{13}$ This was counter checked in all the cases by hand held Doppler. ${ }^{8}$ In an person of average build the proximal calf provides up to $22 \times 12 \mathrm{~cm}^{2}$ tissue to cover larger defects. In our cases the average size of the defect was $10 \times 10$ $\mathrm{cm}^{2}$. We used such flaps even for defects involving the entire sole $\left(21 \times 11 \mathrm{~cm}^{2}\right)$. On these occasions we kept the base of the flap wide and utilized it to cover the rest of the defect after detachment. In rest of the cases, the pedicle and the base was narrowed up to $3-4 \mathrm{~cm}$ and was brought back to the donor limb at the time of detachment.

The limiting factors like inconvenience, discomfort and hospitalization for four weeks are relatively insignificant as compared with the benefits achieved in those challenging situation. We feel that cross leg flaps are very reliable flaps for lower leg and foot defects if properly designed and transferred in selective cases where other flaps are expected to be risky or not feasible. This time honored technique for coverage of soft tissue defect still has many applications for wounds of leg and foot in spite of emergence of newer techniques and should not be abandoned altogether.

\section{CONCLUSIONS}

Retrograde cross leg perforator flaps are reliable option in cases of failed free flaps, unavailable ipsilateral proximal tissue, damaged distal perforators and distal most defects of foot. When compared with the conventional cross leg flaps the discomfort, cross legging, joint stiffness and sore development are minimal. Hence, these flaps must be considered in demanding conditions and not to be deserted just because of other available techniques.

\section{REFERENCES}

1. Barclay TL, Cardos E, Sharpe DT. Cross leg fasciocutaneous flaps. Plast Reconstr Surg 1983;72:847.

2. Tolhurst DE, Haeseker B, Zeeman RJ. The development of fasciocutaneous flap and its application. Plast Reconstr Surg 1983;71:597.

3. Mathes S, Nahai F, editors. Clinical application for muscle and musculocutaneous flaps. St. Louis: Mosby; 1982.

4. May JW, Gallico GG, Lukash FN. Microvascular transfer of free tissue for closure of bone wounds of the distal lower extremity. N Engl J Med 1982;306:253.

5. Wee JTK. Reconstruction of the lower leg and foot with the reverse pedicled anterior tibial flap:preliminary report of a new fasciocutaneous flap. Br J Plast Surg 1986;39:327.

6. Yoshimura M, Imura S, Shimamura K, Yamuchi S, Nomura S. Peroneal flap for reconstruction in the extremity. Plast Reconstr Surg 1984;74:402.

7. Morris AM, Buchan AC. The place of the cross leg flap in reconstructive surgery of the lower leg and foot:a review of 165 cases. Br J Plast Surg 1978;31:138.

8. Taylor GI, Doyle M, McCarten G. The Doppler probe for planning flaps: Anatomical study and clinical applications. Br J Plast Surg 1990;43:1-16.

9. Carriquiry C, Costa A, Vasconez LO. An anatomic study of the septocutaneous vessels of the leg. Plast Reconstr Surg 1985;76:354.

10. Haertsch PA. The blood supply to the skin of leg. A Post mortem investigation. Br J Plast Surg 1981;34:470.

11. Jayes PH. Cross leg flaps: A review of sixty cases. Br J Plast Surg 1950;3:1.

12. Ponten $B$. The fasciocutaneous flap. Its use in soft tissue defects of lower leg. Br J Plast Surg 1981;34:215.

13. Carriquiry C, Costa A, Vasconez LO. An anatomic study of the septocutaneous vessels of the leg. Plast Reconstr Surg 1985;76:354.

14. Bhattacharya V. Fasciocutaneous flaps in Plastic and Reconstructive surgery: Current trends- proceedings of CME programme at National Conference of APSI, Calcutta, 1998. p. 36-40.

15. Bhattacharya V, Watts RK. Ipsilateral fasciocutaneous flap for leg and foot defects. Indian J Plast Surg 2003;36:30-5. 